\title{
VIMALA DEVI, IDA VITALE E GABRIELA MISTRAL: DIÁSPORA AO FEMININO OU A LUSOFONIA EM \\ DIÁLOGO
}

VIMALA DEVI, IDA VITALE AND GABRIELA MISTRAL:

WOMEN, DIASPORA AND A LUSOPHONE CROSS-

CULTURAL EXCHANGE

Carolina Cunha Carnier

Doutora em Literatura Francesa e Brasileira pela Universidade de Lyon e Universidade de São Paulo.

Via Atlântica, Săo Paulo, n. 38, pp. 363-400, dez. 2020. 
Resumo: A América Latina e certos territórios coloniais europeus da África e Ásia, apesar de contextos diversos, são terrenos de convergência de formas poéticas que problematizam a memória e o exilio. Se muito já se disse sobre a influência da obra de Gabriela Mistral na escrita de autores diversos, é inédita, no entanto a aproximação de seu lirismo com as representações da Montevideo de Vitale, bem como com as relações ao sensível explícitas nas representações de Goa de Devi. Concentro-me, respectivamente, nas três partes dessa análise, em uma seleção de poemas de Procura de lo Impossible (1998) de Ida Vitale, Poema de Chile de Gabriela Mistral (1967) e de Súria (1962) de Vimala Devi.

Palavras-chave: poesia feminina, memória, exilio, pós-colonial. 
Abstract: Latin America and certain European colonial territories in Africa and Asia, despite different contexts, are areas of convergence in poetic forms that problematize memory and exile. If much has already been said about the influence of Gabriela Mistral's work in the writing of different authors, however an approach between her work and the representations of Montevideo by Vitale is unprecedented, as well as to its relations to the sensitive representations of Goa from Devi. I focus, respectively, on the 3 parts of this analysis, in a selection of poems from Busca de lo impossible (1998) by Ida Vitale, Poema de Chile by Gabriela Mistral (1967) and Súria (1962) by Vimala Devi.

Keywords: women poetry, memory, exile, postcolonial. 
Assunto extremamente presente na atualidade de nossas sociedades globais, as migrações e os consequentes deslocamentos por elas produzidos impõem constantemente uma leitura crítica do mundo. As obras de arte produzidas nestes contextos questionam as noções, ainda extremamente pertinentes, de identidade e pertencimento relacionadas às fronteiras nacionais e aquelas, diversas vezes atualizadas, que constroem afetivamente para si os indivíduos em migração. Os termos diáspora, exílio - e as chaves epistemológicas produzidas por esses signos - colaboram com as tentativas de compreensão desses fenômenos sociais que, considero, têm implicações políticas e, para os especialistas da literatura e das ciências humanas, filosóficas. Pensando num aparato teórico capaz de abarcar esses conceitos, recobertos de sistemas axiológicos próprios ou não, torna-se imperativo um trabalho comparatista afim de melhor compreender os processos internos e particulares à cada sistema e sobretudo resignificá-los face a atualidade. Proponho uma leitura de três sistemas diversos e com o corpus literário que segue: Súria (1962) de Vimala Devi, Procura de lo impossible (1998) de Ida Vitale e Poema de Chile (1967) de Gabriela Mistral. Concentro-me aqui na análise de textos nos quais é flagrante a representação da experiência exílica, em suas diversas e subjetivas formas. Ademais, as obras selecionadas foram todas escritas em um contexto diaspórico. Adoto, aqui, o conceito de diáspora de- 
senvolvido pela socióloga Avtar Brah nos termos que seguem:

Las diásporas, como experiencias históricas distintivas, a menudo son formaciones compuestas por muchos viajes a diferentes partes del globo, cada una con su propia historia, sus propias particularidades. Cada diáspora es un cruce de múltiples viajes; un texto de narraciones exclusivas y, quizás, incluso dispares. [...] sugiero que se entienda el concepto de diáspora como 'genealogías' históricamente contingentes en el sentido foucaultiano; esto es, como un conjunto de tecnologías de investigación que construyen la historia de las trayectorias de diferentes diásporas, y analizan sus relaciones a través de los campos de lo social, la subjetividad y la identidad. (BRAH, 2011, p. 214)

Esses três pontos descritos por Brah - o aspecto social, a subjetividade e a identidade - orientarão minha análise das três poetas: Vimala Devi de Goa, Gabriela Mistral do Chile e Ida Vitale, Uruguai. Trabalharei, portanto, a experiência do exílio no que esta revela das instâncias de poder agindo articuladamente constituindo, por sua vez, um conceito de diáspora representada na poesia de cada autora. Quanto ao que chamo de "experiência do exílio" ou "experiência exílica", faço referência ao conceito desenvolvido por Alexis Nouss no qual estas são, ao mesmo tempo, condição e consciência, dotadas de potencialidade heu- 
rística ${ }^{1}$. Elas são ao mesmo tempo, e ainda segundo Nouss, reivindicadas como construção identitária e operadoras de uma reflexão memorialística como condição passível de ser partilhada por todos.

Mas ainda, porque a aproximação entre as poéticas dessas autoras, em particular? A América Latina, com o advento dos regimes militares ou ainda as revulsões políticas do início do século XX, foi um terreno a partir do qual uma série de textos se desenvolveram tendo como particularidade as experiências do exílio. Ainda, no mesmo período e nos territórios dos impérios coloniais europeus em desaparecimento, desenvolvem-se textos que discutem temas tais quais o pertencimento e identidade em um mundo globalizado no qual os indivíduos entram constantemente em contato nos percursos de migração. Apesar de situações de deslocamentos e de desenraizamentos diversas, estes dois movimentos são um espaço de diálogo para o interior do qual convergem experiências similares como veremos em detalhe com as análises de cada poema. Além disso, as obras aqui revistas foram escritas em um contexto de diáspora. Os modos pelos quais esse corpus trata da condição inerente ao exílio e as imagens produzidas em relação ao "país

1 Penso no livro La condition de l'exilé. Penser les migrations contemporaines, Paris: Maison des Sciences de l'Homme, 2015, mas particularmente os estudos nos quais Nouss introduz e discute o conceito de "exiliência" : Exiliance: condition et conscience e L'exil comme expérience, respectivamente os números 44 et 43 da publicação do seminário L'EXPÉRIENCE DE L'EXIL da Fondation Maison des Sciences de l'Homme, Collège d'études mondiales, de setembro de 2013. 
natal", ao "espaço original" são dos mais relevantes a uma crítica dos modelos poéticos que se caracterizam pelas circunstâncias de migração².

A perspectiva comparatista é pertinente porque permite uma melhor compreensão da diáspora lusófona na intersecção com outros processos migratórios, marcados por fatos históricos diferentes, na confluência de línguas diversas. E mais importante, nessa intersecção encontra-se ainda uma leitura feita por mulheres da confluência linguística e cultural proporcionada pelas migrações. A escrita destas três autoras prenuncia, ao contrário do que afirma uma leitura essencialista, a procura de uma partilha se não

2 Gabriela Mistral afirma em 1952, em carta à Doris Dana, amiga e secretária, ter finalizado seu Poema de Chile. Os poemas que compõem a saga mistralina foram escritos ao longo de 20 anos e, logo, produzidos anteriormente ao golpe militar de 1973. Entretanto, Mistral escreve à margem da página 299 do manuscrito de Poema de Chile (rolo 1, caderno 1, microfilme disponíveis na Biblioteca Nacional de Chile, Santiago), uma lista de disposições em relação a sua antologia, dentre as quais "contar finamente el que no me dejan volver", como afirma Soledad Luco Falabella em 'Desierto': Territorio, desplazamiento y nostalgia en Poema de Chile de Gabriela Mistral, cf. bibliografia citada. Para além de uma escrita de resistência ou marcada de modo indelével pelas violências dos regimes militares, defendo uma imagem do país natal modulada pelo exílio e exílio orientado pelo feminino, seja este declarado ou velado. Ademais, no caso de Mistral, será o deslocamento e as consequências da translação representada que importarão nas análises aqui presentes, particularmente no que o sofrimento e nostalgia do exílio se conjugam com um profundo ressentimento em relação a uma determinada elite intelectual, e marcadamente masculina, chilena. A imagem do Chile produzida a partir do exílio é o produto dessa conjugação e é sobre essa imagem que me concentro neste trabalho. É no âmbito desta forma de dor essencial, ferida original, que é possível aproximar a representação de Mistral daquelas presentes nas obras de Vitale e Devi. 
universal, ao menos transversal da representação do mundo feita por mulheres nas sociedades do Global South.

Tratarei num primeiro momento do modo pelo qual Ida Vitale transpõe a experiência exílica. Esta torna-se deslocamento, espaço de novos diálogos com autores de várias épocas, mas também contemporâneos. 0 exílio e a diáspora que aqui se constituem navegam por outros discursos, outros contextos históricos e sociais de modo a representar a experiência em constante transformação que define cada diáspora. Num segundo momento abordarei uma seleção de poemas de Poema de Chile de Mistral no qual estão presentes uma relação particular e transcendente à natureza, uma identidade que se liga a ela e que é contingente a uma imagem do ser mulher, aspecto este que engloba a relação com os povos autóctonos do Chile. Por fim, analiso uma seleção de poemas presentes em Súria de Vimala Devi a partir de dois pontos: o primeiro concerne a utilização de elementos exóticos, em uma continuação da tradição romântica, como crítica ao modelo colonial. 0 segundo expõe a condição do indivíduo como ponto para o qual convergem um conjunto heterodoxo formado por múltiplas viagens, discursos, línguas e culturas. Passemos a Ida Vitale e vejamos de que modo a diáspora representada por sua poesia dialoga com outros discursos e enriquece, por esse diálogo, a experiência exílica que lhe é particular. 
1. Ida Vitale: "[...] las desoladas quemazones/ sobre una tierra distraída/ de lo que un día hubiera sido (VITALE, 2017, p. 223)"

Ida Vitale nasce em Montevideo em 1923. Integra o grupo que seria mais tarde conhecido como "Geração de 45", do qual fizeram parte, ainda, Juan Carlos Onetti, Carlos Maggi ou Idea Vilariño, grupo em grande medida influenciado por pensadores como Angél Rama. Com o golpe de Bordaberry em 1973, Ida Vitale se exila no México graças aos contatos, entre outros, com o crítico Octavio Paz. Em relação ao exílio mexicano, Vitale afirma:

Los años mexicanos fueron riquísimos de experiencias de todo tipo. La del exilio sólo puedo compararla con la creciente del Nilo, que parece una catástrofe que todo lo arrasa, pero que al retirarse deja más fértil el terreno. [...] Junto a tanto desgarramiento descubrimos la apertura, la generosidad del mundo cultural mexicano. Ese es un sedimento que combate toda la aridez posterior, incluso la de vivir dentro de otra lengua. (MASCARÓ, 1993)

É a partir dessa imagem de fertilidade poética ocasionada pelo exílio que se concentram as análises da primeira parte deste estudo. De 1973 a 1984, Ida permanece no México, voltando ao Uruguai de 1984 à 1988. A partir de 1989 muda-se para Austin, Texas, onde permaneceu até início de 2018, quando volta então a Montevideo. A obra de Vitale tem recebido os 
mais importantes prêmios atuais na categoria poesia, dentre eles em 2009 o IX Prêmio Internacional Octavio Paz de Poesia e Ensaio (dividido com Ramón Xirau); em 2014 o Prêmio Internacional Alfonso Reyes; em 2015 o XXIV Prêmio Reina Sofía de Poesia Ibero-americana; em 2016 o Prêmio Internacional de Poesia Federico García Lorca; em 2017 o Prêmio Max Jacob e, enfim em 2018, o Prêmio Cervantes pelo conjunto de sua obra.

Em relação à problemática que aqui nos ocupa, a obra da poeta uruguaia revela relações preciosas. Ao contrário de Vimala Devi e Gabriela Mistral, a situação de diáspora não é tratada de modo explícito. Vitale é, ainda hoje, extremamente discreta quando indagada sobre suas experiências de exílio ${ }^{3}$. Entretanto, muitas imagens estão presentes a esse respeito na profícua obra da autora, que se estende de 1946 até os dias atuais. Os poemas escolhidos como corpus dessa segunda parte fazem parte da antologia Procura de lo impossible (1998), que se divide em oito partes: Soltar el Mirlo; Imágenes del Mundo Flotante; Tropelía; Jardines Imaginarios; Arder, callar; Terquedad de lo Ausente; Presencias; e La Voz Cantante. Em sua maioria, cada uma dessas subdivisões é introduzida por referências literárias que vão desde autores medievais e do século de ouro espanhol, aos clássicos britânicos, ao renascimento europeu e aos escritores latino-ame-

3 A autora lançou em 2019 Shakespeare Palace, obra em que relata os 11 anos passados em exílio no México, cf. ref. bibliográficas. 
ricanos contemporâneos à Vitale. Dentre os escritores citados estão Salvador Espriu, Shakespeare, San Juan de la Cruz, E.E. Cummings, Richard Barnefield, Paul Auster, M. Moore, Luis G. Urbina, René Char, Oliverio Girondo, Francisco de Aldana, Pablo Neruda, Octavio Paz e Raimbaut d'Orange. A grande erudição de Vitale se apresenta ainda em seu trabalho de tradução com obras de Simone de Beauvoir, Tout compte fait (1972), de Benjamin Péret, em um conjunto de contos presentes em obras diversas ${ }^{4}$ - e Gaston Bachelard La Poétique de la Rêverie (1960) ${ }^{5}$. Ao contrário de Gabriela Mistral, a reivindicação de uma identidade latino-americana, ou mesmo uma identificação com os povos originários do Uruguai não é problematizada por Vitale. Nesse ponto, sua poética e as representações presentes em sua obra aproximam-se da escrita de Vimala Devi, inclusive no que se refere ao trabalho de tradução e mediação feitos por essas duas autoras entre as várias línguas presentes nos deslocamentos de seus percursos respectivos, como veremos na terceira parte desse estudo.

Comecemos com o poema "Exilios" da antologia de 1998 Procura de lo Impossible.

4 Pulquería Quiere Un Auto Y Otros Cuentos. Introdução de Octavio Paz. México: Editorial Vuelta, 1996.

5 La poética de la ensoñación. México : Fondo de Cultura Económica, 1982. 


\section{EXILIOS}

tras tanto acá y allá yendo y viniendo

Francisco de Aldana

Están aqui y allá: de passo,

en ningún lado

Cada horizonte: donde un ascua atrae.

Podrían ir hacia cualquier grieta.

No hay brújula ni voces.

Cruzan desiertos que el bravo sol

o que la helada queman

y campos infinitos sin el limite

que los vuelve reales,

que los haría casi de tierra y pasto.

La mirada se acuesta como un perro,

sin el tierno recurso de mover una cola.

La mirada se acuesta o retrocede,

se pulveriza por el aire,

si nadie la devuelve.

No regresa a la sangre ni alcanza

a quien debiera.

Se disuelve, tan sólo. (VITALE, op. cit., p. 229)

Um dos raros exemplos da representação do exílio em Vitale, esse poema abre a antologia Procura de lo Impossible. Diferentemente do que encontramos em Vimala Devi, a experiência aqui descrita não é feita em primeira pessoa. Uma distância essencial, e extremamente característica do estilo de Vitale, permeia todo poema e se conjuga com as mais diversas referências intertextuais a fim de estabelecer o lugar a partir do qual a experiência do exilio pode ser re- 
presentada. Neste poema, o intertexto invocado por Vitale passa pela citação, mot à mot, de um dos sonetos de Francisco de Aldana: poeta do século XVI, da chamada segunda fase do renascimento espanhol. 0 verso de epígrafe de Aldana faz parte do soneto Reconocimiento de la vanidad del mundo:

[...]En fin, en fin, tras tanto andar muriendo,

tras tanto varïar vida y destino,

tras tanto, de uno en otro desatino, pensar todo apretar, nada cogiendo, tras tanto acá y allá yendo y viniendo, cual sin aliento inútil peregrino, ¡oh, Dios!, tras tanto error del buen camino, yo mismo de mi mal ministro siendo, hallo, en fin, que ser muerto en la memoria del mundo es lo mejor que en él se asconde [...] (DE ALDANA, 2003, p. 283-284)

Com esta referência, Vitale faz uso do tema do peregrino e o aproxima da experiência vivida pelo sujeito em um contexto diaspórico. É importante notar o fato de, nesse excerto, a mobilidade do sujeito implicar na relação com a memória. De Aldana trata do "ser morto na memória do mundo ${ }^{6 ", ~ d o ~ m e s m o ~ m o d o ~}$ que Vitale trata da relação entre o "olhar" do sujeito e as relações neste ato implicadas. 0 peregrino olha o universo novo no qual se encontra, mas sem a reciprocidade do outro - "si nadie la devuelve" - esse olhar "pulveriza-se", “dissolve-se". O olhar que se dissolve, que aqui torna-se a metonímia do peregri-

6 Tradução nossa. 
no, pode ser aproximado da leitura feita por Aldana do apagamento da memória no espaço exílico. 0 peregrino torna-se componente ambulante dentro de um mundo que, pensa-se, estanque, perene, como descrevem os primeiros versos: "Están aqui y allá: de passo,/en ningún lado": se o peregrino está em "lado nenhum", diferencialmente existe uma perspectiva na qual a estabilidade dos sujeitos é possível. Importante notar que o verbo "estar" aqui marcaria, nessa lógica, uma forma de pertencimento, uma identificação a um espaço físico, um primeiro passo a uma nova composição das identidades. Sabemos, no entanto, que as realidades impostas pelas situações de migração, especificamente os incessantes e cada vez mais frequentes deslocamentos de populações, impõem uma releitura dos territórios de acolhimento, os estados e nações que são ponto de chegada dos sujeitos em migração. Esses próprios espaços se modificam com as diásporas. Compreender dessa forma essas mutações reverteria, assim, a condição que define as pessoas em situação de exílio, para quem "no hay brújula ni voces".

Dentre as novas marcas que orientam o exílio, encontra-se o estranhamento que é por vezes representado em Vitale com a palavra "vozes", que seja em uma relação dialógica entre silenciamento do que se foi, ausência do que antes era familiar - espaços, linguagens, palavras - e a presença experimentada de um conjunto de novas formas do existir em situações 
de exílio. Vejamos como essa dicotomia se estrutura em Vitale com o exemplo do poema que segue.

ARDER, CALLAR

\section{Y ardamos, y callemos, y campanas}

Pablo Neruda

Sin lar, sin can, sin cala,

callar como precipitarse,

mientras arde

la ansiosa fiesta del efímero otro.

(Abominable yo de mambo y rumba,

un yo de Rambo

que trepa a la veleta

de la pobre provincia

y desvaría glorias y gira solo,

en seco.

Sin ver que el viento

interrumpido

va de otras torres, de otras almenas

altas y lejanas.)

Entonces, por qué no, precipitarse en lo olvidado, donde entre rocas ruge el río y ráfagas repasan la corteza, esta seca corteza del mundo, en que paramos, siendo todo anulado y repetido.

Y aquietarse y con suerte sentir en

el inmenso, interior campo,

un sonar de campanas hermanadas. (VITALE, op. cit., p. 233)

Como afirmado anteriormente, as referências em Vitale não são anódinas e fazem parte de seu pro- 
cesso de criação. Sua poesia, as experiências que ela representa, partem das ou encontram ecos possíveis nas escrituras do outro. Exemplo desse processo encontra-se no poema "Exilios" e neste último; "Arder, callar", dentre diversos outros como, ainda, a antologia de 1949, La luz de esta memoria. Vemos nessa antologia, em num estágio inicial da escrita de Vitale, uma tensão particular na relação entre a construção memorialística e uma identidade ligada ao nacional e às fronteiras geográficas que definem - de modo precário- o pertencimento do sujeito a um grupo determinado. Lemos, assim, um excerto de Lope de Vega, que abre o poemário: "a pesar de la sangre que procura/cubrir de noche oscura/la luz d'esta memoria"7. Em "Arder, callar"; a formação da memória aparece, num estágio mais avançado da escrita da poeta, ligada ao esquecimento- que pode referir-se também à forma de silenciamento intrínseca ao exílio sobre o qual re-

$7 \quad$ Vitale retoma o seguinte trecho de Lope de Vega :

"[...]Yo os di la mejor patria que yo pude para nacer, y agora en vuestra muerte, entre santos dichosa sepultura;

resta que vos roguéis a Dios que mude mi sentimiento en gozo, de tal suerte que, a pesar de la sangre que procura cubrir de noche escura la luz de esta memoria, viváis vos en la mía [...] que espero que algún día la que me da dolor me dará gloria, viendo al partir de aquesta tierra ajena, que no quedáis adonde todo es pena", Obras Poeticas, ed. José Manuel Blecua, Barcelona: Planeta, 1969, p. 485-486, grifo nosso, retomando a epígrafe escolhida por Vitale. 
feri-me anteriormente. Vitale está aqui a falar daquilo que diz o mundo sob um ponto de visto do exílio, leitura que pode ser feita através dos versos da primeira estrofe: "Sin lar, sin can, sin cala / callar como precipitarse, / mientras arde/ la ansiosa fiesta del efímero otro". Estar em exílio é precipitar-se no outro, despido daquilo que antes definia o que éramos, o que fomos: "ar", "can", "cala". Esta "ansiosa festa do efêmero outro", que é a experiência de migração, se representa aqui com a metáfora da interrupção. Quando se deixa o país natal, algo se rompe: projetos, rotinas, paisagens familiares... 0 "vento" que agora sopra é estranho, distante: "el viento/ [...] va de otras torres (...) altas y lejanas". É nessa relação de distância que se encontra ou se confronta com a alteridade. Encontra-se o outro nessa interrupção que é também um "precipitar-se", "en que paramos, / siendo todo anulado y repetido", na "seca corteza del mundo". Curiosamente, a palavra "corteza" pode referir-se, em português, aos vocábulos "crosta", como a terrestre; "casca”, como a de uma árvore; ou ainda pode referir-se à massa cerebral. Os mesmos caminhos que nos levam ao outro, ao desconhecido, se misturam com o que se liga ao enraizamento, à memória, ao cérebro e suas lembranças. No exílio isso se perde num movimento involuntário. Vitale propõe então, ir ao encontro do outro e descobrir, "com sorte", fraternidades antes desconhecidas: "Y aquietarse y con suerte/ sentir en / el inmenso, interior campo, /un sonar de campanas hermanadas". E o 
modo proposto pela poeta afim de entrar em contato com a alteridade é precipitar-se naquilo que foi esquecido: "por qué no, / precipitarse en lo olvidado?".

Nesse sentido, é com a epígrafe deste poema que Vitale encontra solidariedade na história e poesia "hermanadas" de Pablo Neruda. Vitale retoma o último verso do poema Entrada a la madera, recolhido em Tres cantos materiales de Residencia en la tierra: "[...] y hagamos fuego, y silencio, y sonido, / y ardamos, y callemos, y campanas" (NERUDA, 2004, p. 149). Se discursivamente podemos estabelecer diálogos entre o que conta a poesia de Vitale e a de Pablo Neruda, fica evidente a similaridade entre as histórias dos dois poetas. Neruda é um dos nomes mais importantes da literatura chilena, cujos engajamentos políticos levaram a seu assassinato doze dias após o golpe de estado chileno, enquanto Ida Vitale, além de ser, hoje, um dos nomes mais importantes da poesia escrita em espanhol, deixa Montevideo por suas posições políticas após o golpe de Bordaberry.

Como já afirmado, está presente nesse poema a dicotomia entre o calar e a erupção de uma fala que se endereça à alteridade ou a esta se relaciona. Note-se que a questão do feminino não se apresenta em Vitale de modo explícito, nem tão pouco segundo as representações de seus contemporâneos. Logo, a relação ao outro se estabelece, afirmo, numa dinâmica dialógica no terreno do saber, da erudição e não se contendo às questões, certamente subjacentes, de gênero. A 
dicotomia citada se organiza no exercício contínuo de afirmação da experiência pessoal em exílio e numa relação constante com a memória e suas representações. É nesse contexto que uma voz, feminina e sul-americana, ocupa o espaço literário reiterando aquilo que foi e é vivido nas experiências de migração. Nesse sentido, o sujeito aceita a transformação do esquecimento, de quem se era, dos lugares familiares e com ele as representações sociais e políticas do feminino. Similar representação, estreitamente correlata com os movimentos diaspóricos, ocorre na obra de Mistral. No entanto, é um outro diálogo de alteridade que os deslocamentos provocam na representação do feminino na obra da poeta chilena que veremos agora.

2. Gabriela Mistral: "[...] porque todo lo ha olvidado, / menos un valle y un pueblo (MISTRAL, op. cit., p. 21)"

Gabriela Mistral, nome de autora escolhido por Lucila de María del Perpetuo Socorro Godoy Alcayaga, nasceu em 07 de abril de 1889 em Vicuña, no vale do Elqui, região norte do Chile, e morreu em 10 de janeiro de 1957 em Nova York. Mistral é educadora, pedagoga e exerce funções diplomáticas ao longo de sua vida e é considerada um dos maiores nomes da literatura chilena. Recebe, em 1945 o prêmio Nobel de Literatura. Se esse prêmio já se constitui como de im- 
portância inquestionável para as letras chilenas, ele dá visibilidade internacional à literatura produzida no espaço da América Latina. Em seu discurso de recebimento desse prêmio, Gabriela Mistral afirma que o sul do continente americano é terreno cujas produções artísticas e culturais são ainda pouco conhecidas do público do hemisfério norte. Nessa mesma elocução, define-se como filha da democracia chilena e como representante direta dos "poetas de sua raça" e "não daqueles vindos dos espaços dos impérios colonialistas". Afirma ainda estar, indiretamente, "ligada às nobres línguas espanhola e portuguesa”. Essa filiação não é anódina: seu discurso, sua escritura poética, estão permeados por essa visão política que marca, consequentemente, a imagem de uma identidade particular, pois como afirma Avtar Brah em entrevista ao jornal coletivo espanhol El Salto, "a identidade é sempre uma construção política" (CASTILLO CEREZUELA, 2018, tradução nossa).

A identidade em Mistral, e de modo particular em Poema de Chile, estará estreitamente ligada aos deslocamentos. Mistral escreve seu poema épico que tem por objeto o país, sua população, as mazelas sociais, econômicas e a geográfica chilena além de problematizar o papel da mulher nesse complexo espaço que é o território "original". É importante notar-se que Mistral escreve seu Poema ao longo de 20 anos nos quais encontra-se no exterior, tendo deixado o Chile pela primeira vez em 1922. As imagens e o modo 
pelo qual descreve o seu Chile particular é então modificado diretamente pela experiência do exílio. Este torna-se uma espécie de descoberta, espaço próprio à criação poética no qual se encontram identidade, pertencimento e questionamento do que nos constitui enquanto indivíduos. Nesse sentido, é no contato com o outro - alteridade, outras paisagens, outros modos de articular a língua face as contingências da viagem e dos deslocamentos- que o sujeito se modifica: " $A l$ tomar distancia, el sujeto desplazado debe continuamente enfrentar-se, motivado por el dolor, a un 'continuum' reelaborativo de no sólo la imagen del origen, sino que también de su propia identidad" (LUCO FALABELLA, 1997, p. 83). Nesse ponto, o processo poético de Mistral assemelha-se ao de Vitale. Se as relações intertextuais constroem conjuntamente uma poética própria, sem questionamentos nacionais em Vitale, em Mistral a poesia torna-se espaço da territorialização ${ }^{8}$ e afirmação de uma forma de memória nacional, em uma comunhão e, por vezes, indefinição entre o sujeito, a paisagem, o outro e um conceito de nação. É pelo fato de estar fora do espaço original, em terreno estrangeiro, que a poética de Mistral particulariza a representação do Chile. Assim, como o espaço que representa a antologia Tala (1938), território de questionamento da relação do sujeito com a pátria (LUCO FALABELLA, ibidem, p. 86), trata-se de construir-se a

8 Inspiro-me aqui na relação entre a noção de território e os espaços de escrita literária estabelecida por Luco Falabella, op. cit. 
partir de uma ferida original, em consonância com a imagem múltipla e por vezes contraditória em relação à nação e ao país dos quais está longe o sujeito.

Vejamos estas articulações com o poema "Hallazgo", "descoberta":

\section{HALLAZGO}

Bajé por espacio y aires y más aires, descendiendo, sin llamado y sin llamada por la fuerza del deseo, y a más que yo descendía era mi caer más recto y era mi gozo más vivo y mi adivinar más cierto, y arribo como la flecha éste mi segundo cuerpo en el punto en que comienzan Patria Madre que me dieron.

¡Tan feliz que hace, la marcha!

Me ataranta lo que veo lo que miro o adivino lo que busco y lo que encuentro; pero como fui tan otra y tan mudada regreso, con temor ensayo rutas, peñascales y repechos, el nuevo y largo respiro, los rumores y los ecos. 0 fue loca mi partida o es loco ahora el regreso; pero ya los pies tocaron bajíos, cuestas, senderos, gracia tímida de hierbas y unos céspedes tan tiernos que no quisiera doblarlos 
ni rematar este sueño

de ir sin forma caminando

la dulce parcela, el reino

que me tuvo sesenta años

y me habita como un eco.

Voy en delgadez de niebla pero sin embargo llevo las facciones de mi cara, lo quebrantado del peso, intacta la voluntad pero el rostro medio ciego y respondo por mi nombre aunque ya no sea aquélla. (MISTRAL, 2015, p. 17-18)

O primeiro ponto que chama a atenção é a assimilação da Pátria à imagem materna. Longe de ser algo novo, a figura materna é aqui reproduzida em seu aspecto fixo e circunscrito na única ação de protagonismo e ação política que é a figura da mãe protetora, educadora e aqui permeada pelos elementos da natureza chilena. Mas essa pátria se configura de modo não ortodoxo e por vezes contraditório. Ela é lida e representada por uma mulher nômade e autônoma. Mas que acolhe, acalenta e ensina. Ela é ativa e ordena os saberes do mundo nos deslocamentos e itinerâncias narrados verso a verso. Além disso, note-se as grafias em maiúscula das palavras "Pátria" e "Madre". Longe de serem meros artifícios visuais, a diferenciação gráfica marca verdadeiras entidades. Outro aspecto a se sinalizar aqui é o deslocamento. Se em sua integralidade o livro é composto em uma voz em primeira pessoa que se move dentro do espaço 
geográfico que é o Chile, como país, como território físico, não se deve esquecer que Mistral escreve a partir do exterior. Logo, a referência em relação ao que faz parte do país é alterado pelo imaginário e pelas experiências do exterior. Assim, "Hellazgo" torna-se o espaço da afirmação de uma nova identidade, ainda estreitamente ligada à "Pátria Mãe" ou "Tierra Mama", mas de modo outro daquele de quando se partiu: "fui tan otra / y tan mudada regreso".

Segundo ponto importante é a questão indígena, que permeia toda a obra de Mistral, a própria autora se considera "mestiça", mas é em Poema de Chile que ela aparece de modo mais sintomático, em uma relação de filiação entre a figura feminina, figura materna, e o povo chileno. Vejamos o modo pelo qual essa ligação é representada e como essa poesia repensa, nesse contexto, as questões particulares ao exílio, à diáspora e ao feminino.

\section{AROMAS}

-Cuentan entre los Arcángeles

el que da el aroma denso, y uno es aquél que regala salvia, tomillo y romero y éste no anda en los jardines, porque ha escogido los huertos.

-Mamá, yo nunca lo he visto ¿Será que no anda el Desierto?

¿Será que al indio no quiere?

- ¿Para qué lo quieres ver 
si te repasa en el viento?

-Mamá, tendrá no más que alas

y que se ve sólo en sueños

o no le gustan los indios,

o pasará cuando yo duermo.

Sí, sí, mamá, algo me pasa

cuando al sueño voy cayendo.

Llévanos por donde pasa,

despiértame si estoy durmiendo.

-Pero pasa tan ligero

y tú tienes duro el sueño. (MISTRAL, op.cit., p. 59)

Dois aspectos importantes marcam esse poema. 0 primeiro é o pequeno índio, que acompanha a mulher que narra suas aventuras com um terceiro companheiro de percurso, o pequeno cervo andino. 0 menino e o cervo tornam-se ambos filhos por adoção e partilham dos saberes populares que misturam, em Poema de Chile, catolicismo, personificação e sacralização da paisagem. Tal qual o cervo, o pequeno índio é órfão e é adotado pela mulher que caminha. A profunda relação de afeto entre a mulher e o animal aparecem descritas no poema "Encuentro del ciervo":

ENCUENTRO DEL CIERVO

Nasciste en el palmo último

de los Incas, tú, mi ciervo, donde empezamos nosotros

y donde se acaban ellos;

y ahora tú me guías

o soy yo la que te llevo 
¡qué bien entender tu él alma

y yo acordarme del cuerpo!

Son muy tristes, mi chiquito, las rutas sin compañero [...] (MISTRAL, op.cit., p. 19-22)

A filiação ao cervo marca uma nova solidariedade entre a mulher e o animal. Ela está intimamente ligada às origens, aqui partilhadas. Ambos descendem dos Incas, de um espaço específico - "el palmo último / de los Incas", capaz de federar os seres e impor uma filiação original. E não por acaso, o pequeno cervo será tratado pelos mesmos termos com os quais a mulher faz referência ao pequeno índio que também se torna um de seus filhos: "mi chiquito". A ingenuidade da criança em seus diálogos é de extrema beleza e expõe a importância dos elementos naturais e da geografia encontrada nas relações quotidianas, nos mitos populares e construções folclóricas ancoradas em uma religiosidade sincrética, apesar da prevalência cristã, como no exemplo do verso que afirma que o Arcanjo, também escrito em maiúsculas, passa com o vento: “¿Para qué lo quieres ver / si te repasa en el viento?". O segundo ponto importante é a interrogação do menino: "Será que al indio no quiere?". 0 pequeno de origem indígena conhece a diferença de tratamento que pode existir entre os "outros" e ele, conhece o racismo. Aqui, interpreta nunca ter visto o Arcanjo como a distinção feita em referência a sua cor de pele. 0 pequeno índio é familiar com o espaço geográfico no qual evolui. Entretanto, a população origi- 
nal é privada desse território. Não somente isso, mas o conjunto de valores populares e tradicionais a esse espaço são agora assimilados à opressão colonial na referência do catolicismo e suas figuras angelicais.

Se em Mistral o discurso indigenista passa pela figura materna e pela releitura que consiste no olhar da criança em relação às questões étnico-raciais no Chile, em Vimala Devi a escrita poética passa pela primeira pessoa. Ao contrário do que vemos em Mistral, Devi não opera, em Súria, a ficcionalização das experiências representadas. Vejamos as consequências desse deslocamento discursivo na compreensão do conteúdo "exótico" presente nos versos de Devi e o modo pelo qual uma vertente nacionalista é atualizada com o trabalho da escrita poética.

3. Vimala Devi: "Envolta em odor de sândalo/ Serei a voz [...] de dois mundos!" (DEVI, op. cit., p. 28)

Teresa da Piedade de Baptista Almeida, que escolhe o nome de Vimala Devi como nome de autora, nasceu em 1932 em Britona, Penha de França, Goa. Devi flutua entre línguas diversas-português, devido a história colonial, o inglês pela proximidade com Bombaim, o marathi e kanada dos estados vizinhos, e o concani. Como Ida Vitale, Vimala Devi tem amplo trabalho de tradução e publica antologias bilíngues em português, castelhano, catalão, francês e sânscri- 
to - Plvralogo (1996) e Speguligôj (1998), ambas publicadas pela editora La Kancerkliniko em Thaumiers, França. Devi exerce, ainda, trabalho de crítica de arte para a imprensa, incluindo a BBC londrina. Efetua, em 1960, viagem ao Brasil e em 1964 a Angola e Moçambique.

Súria é seu primeiro livro publicado. Composto de 29 poemas, esta antologia é um terreno no qual estão representados contextos políticos e sociais particulares à Goa, ao império português e a seu projeto colonial. A obra de Devi está marcada pelo retrato de uma sociedade amplamente constituída em um cruzamento discursivo, ideológico e heterolíngue. Devi é tributária de uma tradição literária que é enriquecida tanto por uma literatura religiosa jesuíta, em português, que de uma literatura clássica dos textos sagrados hindus, em sânscrito, mas igualmente da influência de uma tradição inglesa cuja incursão passa por Bombaim. Nesse contexto múltiplo, vem ainda se somar as culturas em marathi, do estado vizinho a Goa, Maharashtra, e aquelas veiculadas, embora de modo marginal, em concani. Deve-se, ainda, considerar a larga importância que as culturas e literaturas europeias exercem no cenário cultural de $\mathrm{Goa}^{9}$. Intriga, no entanto, o uso do português como língua principal nessa literatura, sabendo-se dos "usos estratégicos circunscritos" em

9 É sintomático o fato de a primeira livraria em Goa chamar-se Casa Luso-Francesa. 
suas utilizações ${ }^{10}$. Ao contrário de outras manifestações literárias desenvolvidas nos territórios vizinhos à Goa - em Maharashtra e em Karnataka com literaturas escritas, respectivamente, em marathi e kanada- em Goa não se consolida uma literatura em concani, mas em português. Dentro do complexo contexto geopolítico goano, o uso do português evidencia a tensão identitária particular na poesia e no ethos autoral de Vimala Devi. Prova da flutuação entre o conjunto de valores ligados a Portugal e aquele, "propriamente" goano, é o fato de Teresa da Piedade escolher como nome de autora Vimala Devi. Essa mudança é extremamente significativa para a questão do feminino e, diretamente, para o ethos da escritora. Devi adota, assim, o conjunto das representações que a imagem goana, não-ocidental, diversas dos códigos sociais políticos e filosóficos do ocidente implica. Essa representação assumida pela autora é, no entanto, por vezes contraditória, como a representação do feminino que vimos com os poemas de Gabriela Mistral. 0 incipit do Súria confirma essa tensão e é mais que um símbolo: ele dirige a leitura dos 29 poemas. Se para o leitor não especialista a obra da autora goana poderia evocar um conjunto de estruturas sociais e religiosas rígidas e delimitadas, correspondentes aos clichês ocidentais sobre a cultura

10 Cito aqui o trabalho de Joana Passos (PASSOS, 2008, p. 109). Note-se, ainda, a importância da imprensa como veículo de propaganda dos interesses respectivos subjacentes às utilizações a caráter político do marathi, concani, português e inglês. 
goana, em paralelo ao que se conhece da cultura indiana, com seu incipit, Devi rompe com preconceitos:

“... Eis porque me tornei, ó Irmão, num excêntrico bhaul:

Não tenho amos a acatar, não me vergo a mandamentos, cânones ou costumes,

Nem me sujeito às especiosas distinções

inventadas pela fantasia humana;

Revelo-me tão somente pela alegria que

mana do meu próprio amor fluente...

No amor não há separação possível,

mas união indissolúvel e eterna:

Por isso me rejubilo a cantar e dançar."

Além de uma liberdade flagrante e da reivindicação de uma autonomia radical presente nesse excerto de Narahari, a função social do bhaul, aqui representada é, assim como o ethos de Devi, símbolo de uma heterodoxia profunda. Os bhauls são músicos nômades que produzem cantos religiosos e que subsistem graças às ofertas. Mas sobretudo, caracterizam-se pela negação da separação entre indivíduos, que seja por meio da recusa do sistema de castas, seja por meio da recusa da distinção entre homens e mulheres. Devi, com esse excerto, reivindica essa forma de indeterminação que permeia seus poemas. É pela complexa identidade do sujeito que seus poemas devem ser lidos, na superação das fronteiras, na ausência de nitidez entre os limites do eu e do outro. A partir dessa orientação, Súria reproduz os três eixos temáticos que caracterizam, segundo Joana Passos em seu Literatura goesa em português nos 
séculos XIX e XX. Perspectivas pós-coloniais, as letras de Goa já no século XIX. São esses a releitura de temas religiosos, em uma contextualização da realidade social de Goa no século XX, a transposição romântica do exotismo, conjugado agora a temas, imagens, valores "tipicamente" ocidentais, bem como a crítica, por vezes velada, ao projeto colonial português ${ }^{11}$. Exemplos dessas três vertentes aparecem em Súria, e de modo evidente no poema "Chamdrîm", mas poderíamos ainda citar "Vénus Drávidas" - cujo título evoca de modo claro a tradição clássica ocidental: "As curumbinas esvoaçam/ Por entre arrozais de ouro" - e o poema "Agora" - "De ti me contam histórias tristes:/0 teu abandono/Aos ventos da monção,/Com esta dura realidade/ A queimar-me por dentro...".

Concentremo-nos no primeiro:

\section{CHAMDRÎM}

Vem, Chamdrîm feiticeiro, com a tua luz concreta, Transformar as casas de churtas em casas de prata, E deixar que os fazares penetrem oiteiros Em busca de Bambus com que tecer sobrevivência!

O Mandovi e o Zuari, fios de lágrimas salgadas, Abrigam deuses tisnados e humildes,

11 Note-se o poema de A. Lopes Mendes, A cidade velha de Goa, publicado na Ilustração Goana já em novembro de 1865:

"Por que no pó te revolves

Velha cidade de Goa?

Que hás feito? - Por quê não ousas

Rivalizar com Lisboa?

Que é do teu brilho, o teu nome?

Que tua fama inda soa ?!" (apud PASSOS, 2008, p. 43). 
Que nas noites escuras regressam tristes

Com alforrecas nas redes e com as tonas vazias.

Vem, Chamdrîm, rei do firmamento nocturno,

Perolizar, com as tuas tintas mágicas,

Os troncos nus de curumbins crestados pelo sol

- Velas derretendo no perene meio-dia!

Vem rasgar o mistério das aldeias moribundas Onde serpentes venenosas mordem a noite.

A morte espia os camponeses, no regresso das várzeas, Banhados em suor de terra-com olhos nos pés!

Vem, Chamdrîm, alumiar poços e regatos, Onde mainatos, vergados, lutam com a imundície. Sem ti, o sol tropical ardia crânios...

Por isso, Chamdrîm, és o deus dos pobres!

Chamdrîm, a lua, é divindade humanizada, "deus dos pobres" e clemente face às precárias condições de trabalho e duras condições climáticas. É num contexto de "casas de churtas", de curumbins de costas "crestadas" pelo sol, de "aldeias moribundas" e de "imundície", que circula a divindade, posta a serviço dos pobres e transformando uma realidade social comum a diversos outros contextos do dito terceiro mundo. Entretanto, é Chamdrîm que é invocado, é no espaço do Mandovi e do Zuari ao qual sua influência se circunscreve. Nesse ponto, podemos aproximar a profunda crítica política e social de Devi àquela também presente em Poema de Chile. Notemos que a população representada por Mistral pertence às camadas menos privilegiadas da sociedade chilena, assim como em Devi a população mais 
precária de Goa. Esse poema se inscreve numa tendência de conscientização do fato colonial e, consequente, afirmação das particularidades constituintes de uma identidade goesa possível ${ }^{12}$.

Seguindo a tendência de caráter indianista temos o poema Ternura, no qual são descritos os espaços e imagens típicos da geografia e flora goenses, inclusive com termos em concani: "aroma dos zaiêus", Xiuntém e "espigas de arroz", "coqueiros" que caracterizam o espaço indiano. Do mesmo modo o poema "Lagn" (p. 41) que descreve a cerimônia de um casamento segundo os costumes, com "kalvamtams", "murdangas", "seranguis", "betle" e "chondor-vatt" (cujas significações podem ser encontradas nas "notas" ao fim da antologia, preciosas para o leitor não-familiar com as tradições dialetais de Goa).

Entretanto, esse indianismo, ao contrário de uma imagem idílica por vezes projetada pelos discursos ocidentais ${ }^{13}$, deve ser considerado em sua complexidade. Assim como as identidades dos indivíduos que navegam em sociedades culturalmente heterogêneas, como a de Goa, a imagem da identidade dos sujeitos deve ser compreendida em um processo, flutuante e recorrentemente atualizadas, como no poema "Goa":

12 Note-se, no entanto, que uma dicotomia se estabelece ao longo da produção de Devi na qual a afirmação do império se conjuga às particularidades de Goa. Nesse sentido ver recente artigo de Paul Melo e Castro e de Joana Passos no número 36 de Via Atlântica, cf. referencias.

13 Vide, por exemplo, o poema que fecha a antologia Súria, Mistério, p. 47. 


\section{GOA}

Na madrugada de lágrimas e esperança,

Teu pranto é o meu.

De ti me vem um apelo

Dolorido e ancestral.

No meu pensamento serás sempre

0 eterno sonho luso

-Comunhão de mosteiros e pagodes.

Ó Súria divino

Esconde-se tímido

Cobrindo de luto

Teus rios e prados!

Calam-se murdangas e batuques;

Mandós são lamentos

Do folclore em agonia... (DEVI, op. cit., p. 27)

O sujeito, assim como a cidade, como a região, é permeado por fluxos diversos. Essa mesma assimilação encontra-se também em Mistral e Vitale: na obra da primeira, as paisagens diversas compõem a heterogênea identidade da mulher em uma fraternidade com o espaço, enquanto na obra da segunda, é na relação de tensão e estranhamento com a paisagem e com o outro estrangeiro que se constitui a imagem de si mesmo. Voltando ao poema "Goa" de Devi, e de modo similar à tensão encontrada em Vitale, existe um "pranto", descrito com "lágrimas", mas também com "esperança”. Existe um "apelo ancestral”, uma retomada das origens. Entretanto, aí também estão presentes o "folclore em agonia" e as expressões "lamento", 
"apelo dolorido", "eco abafado", num território que é, ainda, a "comunhão de mosteiros e pagodes", "eterno sonho luso". Essa identificação com o espaço é uma das grandes recorrências nas literaturas contemporâneas e esse processo se amplifica ainda nos dias de hoje. Seguindo as mutações de sociedades globais, pós-coloniais, busca-se o que nos representa no caos intrínseco aos espaços que nos cercam. No caso de Devi e do poema "Goa", subsiste o "sonho luso", mas a natureza sobre o qual este se impôs se cobre de luto, agonia e lamentos.

Concluindo, guiados pelas incursões abertas no campo dos estudos sobre as diásporas e as circunstancias de exílio pelas teorias pós-coloniais, vimos os pontos de contato entre as obras de Vimala Devi, Gabriela Mistral e Ida Vitale, apesar dos contextos por vezes distintos de suas representações do exílio, do país original e da transformação íntima provocada pelas migrações. De modo ainda mais específico, a aproximação de textos dessas autoras do Global South revela estruturas sociais e políticas que envolvem representações diversas e por vezes contraditórias, mas extremamente profícuas do ponto de vista literário, do feminino em contextos de diáspora. Em Vitale, uma voz nasce da confrontação com o outro, nos diálogos intertextuais criados pela partilha das experiências descritas por autores do cânone ocidental. Ainda que a Montevideo de Vitale apareça nos textos do exílio, sua representação se concentra no indivíduo, nos sistemas culturais e 
linguísticos novos sem que o questionamento da figura feminina esteja presente diretamente. Diferentemente de Vitale, em cuja obra a afirmação do nacional está ausente e não se conjuga ao feminino, em Mistral o território chileno em sua totalidade faz parte da imagem do que é o feminino, mas este é em um permanente deslocamento. É numa integração plena entre o povo desta terra e da figura nômade feminina que Mistral afirma sua representação a partir do exterior, numa visão de um exilio permanente da figura que percorre o espaço chileno, espaço ficcionalizado e marcado pela memória acionada em um longo exílio. De modo paralelo, Mistral e Devi, ao contrário de Vitale, afirmam um sentimento particular à terra natal. Em Devi, as contradições em relação ao passado imperial goano estão incessantemente presentes. De um lado a afirmação do que de mais particular Goa apresenta: seu vocabulário, seus cheiros, suas figuras míticas e uma realidade social marcada pela precariedade. De outro, a defesa de um passado de opressão política, social e cultural que buscou o apagamento gradual do que de original os espaços do império apresentavam. Quanto ao feminino, diferentemente de Mistral, a posição na obra de Devi se assemelha à de Vitale: a figura da mulher não aparece problematizada, mas a busca da partilha e comunhão de algo maior que o individual nos percursos exílicos define o sujeito e impõem novas formas de leitura específicas que esse artigo buscou apresentar. 


\section{Referências}

BRAH, Avtar. Cartografías de la diáspora: Identidades en cuestión. Madrid: Traficantes de Sueños, 2011.

CASTILLO CEREZUELA, Queralt. Avtar Brah: "La identidad siempre es un proceso, no un producto final". El Salto, Madrid, 9 abr. 2018.

CASTRO, Paul Melo e. Em torno do fim: Goa tardo-colonial no ciclo de contos Monção (1963) de Vimala Devi. Via Atlântica / USP. São Paulo, n. 36, p. 15-41, 2019.

DE ALDANA, Francisco. $c$ Madrid : Castalia, 2003, pp. 283284.

DE BEAUVOIR, Simone. Final de Cuentas. Tradução de Ida Vitale. Barcelona: Edhasa, 1993.

DEVI, Vimala. Súria. Lisboa: Agência-Geral do Ultramar, 1962.

LUCO FALABELLA, Soledad. "Desierto": Territorio, desplazamiento y nostalgia en Poema de Chile de Gabriela Mistral, Revista Chilena de Literatura, $\mathrm{n}^{\circ}$ 50, p. 79-96, 1997

MISTRAL, Gabriela. Poema de Chile. Santiago: La Pollera Ediciones, 2015.

NERUDA, Pablo. Residencia en la Tierra. Santiago: Editorial Universitaria, 2004.

NOUSS, Alexis. La condition de l'exilé. Penser les migrations contemporaines, Paris: Maison des Sciences de l'Homme, 2015.

NOUSS, Alexis. L'exil comme expérience. FMSH-WP-2013-43, 2013. Disponível em: https://halshs.archives-ouvertes.fr/halshs-00861245/document. Acesso em: 10 out. 2020.

NOUSS, Alexis. Exiliance : condition et conscience. FMSH-WP-2013-44, 2013. Disponível em: https://halshs.archives-ouvertes.fr/halshs-00861246/document. Acesso em: 10 out. 2020. 
PASSOS, Joana. As políticas do cânone: quem se marginaliza e por quê? 0 caso de Vimala Devi.Via Atlântica / USP. São Paulo, n. 36, p. 43-62, 2019.

PASSOS, Joana.Literatura goesa em português nos séculos XIX e XX: Perspectivas pós-coloniais e revisão crítica. Braga: CEHUM, 2012.

PASSOS, Joana. A ambivalência de Goa como imagem do império português e as representações da sociedade colonial na literatura luso-indiana. e-cadernos CES, n. 1, 2008.

PERET, Benjamin. Pulquería Quiere Un Auto Y Otros Cuentos. Tradução de Ida Vitale. Introd. de Octavio Paz. México: Editorial Vuelta, 1996.

VITALE, Ida. La poesía es irremplazable. [Entrevista concedida a Roberto Mascaró]. El País Cultural, 209, nov. 1993. VITALE, Ida. Poesía Reunida. Barcelona: Tusquets Editores, 2017.

VITALE, Ida. Shakespeare Palace: Mosaicos de mi vida en México. Barcelona: Lumen, 2019. 